of spread of the counter-ions from the chains. Despite superficial differences, therefore, this system has certain similarities to the polyelectrolytes considered in earlier papers in the discussion.

Drs. D. Mackay and P. Meares (Aberdeen) reported systematic studies ${ }^{5}$ of electrical conductivity and electro-osmotic water transport through a highly swollen membrane of a phenolsulphonic acid resin in sodium form and in equilibrium with sodium chloride solutions of $0.01-1 M$ sodium chloride at $15^{\circ}, 25^{\circ}$ and $35^{\circ} \mathrm{C}$, and also with mixed sodium and hydrogen forms of resins at two concentrations of electrolyte. These results were interpreted in conjunction with those previously obtained for the self-diffusion of sodium and chloride ions through the same resins. It appears that the conductivity of the sodium form of the resin in contact with very dilute solutions is simply equal to the sum of the ionic mobilities and electro-osmotic velocity; but at higher concentra. tions the conductivity is lower than that calculated in this way. It was suggested that this might be due to decreasing electro-osmotic velocity and particularly to its effect on the mobility of co-ions, which apparently have a different migration mechanism from the counter-ions. The velocity of electroosmotic streaming of solution through the membrane was found to be proportional to the potential gradient.

In contrast to this result, Drs. G. J. Hills, P. W. M. Jacobs and N. Lakshminarayanaiah (Imperial College of Science and Technology, London) reported that they had repeatedly observed that the volume of solution electro-osmotically transported per faraday increased with decreasing current density in the range below 20 m.amp. cm.-2 : the effect seemed to be well outside the experimental errors. However, at higher current densities the anomaly disappeared. Measure. ments on membranes of polymethacrylic acid and phenolsulphonic acid in equilibrium with dilute aqueous solutions of the chlorides of lithium, sodium, potassium, rubidium and cæsium were reported. Water-transport was a little greater with lithium than with cæsium, but considerably greater in the phenolsulphonic acid membrane than in the polymethacrylic acid (for example, 28 moles of water per mole of sodium ion in the former, compared with 11 in the latter). Part of this water might be carried in a solvation sheath and the remainder' by 'electroconvection', that is, by flow of the internal solution. However, attempts to separate the two by calculating a mean electro-convective velocity from a combination of electrical conductivity and selfdiffusion coefficients, using the Nernst-Einstein equation, have not been encouraging. The difficulty probably arises from the non-uniform composition of the mobile medium inside the internal diffuse double layer. In this system, therefore, as in electrophoresis, a more precise model of the double layer seems to be called for if a quantitative treatment of the electrokinetic effects in terms of structure is to be achioved.

Dr. Hills emphasized in a discussion with Prof. Rutgers that he did not think that a classical electrokinetic approach to transport in ion-exchange membranes was appropriate.

J. A. KITCHENER

D. A. HAYDON

${ }^{1}$ Hermans, $J$. Polymer Sci., 28, 527 (1955). Overbeek and Stigter, Rec. Trav. Chim., 75, 543 (1956). Fujita, ibid., 76, 798 (1957). Geelen, Ph.D. thesis (Utrecht, 1958).

${ }^{2}$ Anderson, Proc. Second Int. Congr. Surface Activity, 1957, 8, 67 ; Trans. Faraday Soc., 54, 131, 562 (1958).

${ }^{3}$ ef. Rutgers et al., Trans. Faraday Soc., 48, 635 (1952); 53, 393 $(1957)$.

4 cf. Harmsen, van Schooten and Overbeek, J. Colloid Sci., 8, 64 ${ }^{5}$ ef. Meares, J. Chim. Phys., 55, 273 (1958).

\title{
THE YARD AND THE POUND (AVOIRDUPOIS) FOR SCIENCE AND TECHNOLOGY
}

\begin{abstract}
T HE directors of the following standards laboratories have discussed the existing differences between the values assigned to the yard and to the pound in different countries: Applied Physics Division, National Research Council, Ottawa, Canada; Dominion Physical Laboratory, Lower Hutt, New Zealand; National Bureau of Standards, Washington, United States; National Physical Laboratory, Teddington, United Kingdom; National Physical Research Laboratory, Protoria, South Africa; and National Standards Laboratory, Sydney, Australia. To secure identical values for each of these units in precise measurements for science and technology, it has been agreed to adopt an international yard and an international pound having the following definitions: the international yard equals 0.9144 metre; the international pound equals $0.45359237 \mathrm{kgm}$.

It has also been agreed that, unless otherwise required, all non-metric calibrations carried out by the above laboratories for science and technology on and after July 1, 1959, will be made in terms of the international units as defined above or their multiples or submultiples.
\end{abstract}

The new international units conform with the recommendations of the Board of Trade Departmental Committee on Weights and Moasures Legislation (the Hodgson Committee), but the Board of Trade points out that the units will have no statutory force and may not be used for trade purposes in the United Kingdom. The yard and pound units to be used in trade are the imperial units laid down in the Weights and Measures Act, 1878.

The values of the yard currently in use in the British Commonwealth and the United States of America are as follows, when expressed in terms of the metre : 1 imperial standard yard $=0.9143972$ metre; 1 Canadian yard $=0.9144$ metre; 1 yard as at prosent used by the National Physical Laboratory for science and technology, based on the 1922 value of the imperial standard yard $=0.91439841$ metre ; 1 United States yard $=0.91440183$ metre.

As the imperial standard yard is about 5 parts per million $(0.0002$ inch) less than the United States yard (which is defined in terms of the metre) and is shortening at the rate of more than one-millionth of an inch per annum, the consequent discrepancies in measurements of length are important in modern 
precision engineering. To give two examples, it is necessary to know the lengths of the highest grade block gauges accurately to one part per million, and the permissible error on accurate yard scales is 0.0001 inch. Though the National Physical Laboratory, by using the metre and wave-lengths of light and by adopting the 1922 value of the imperial standard yard in relation to the metre, has been able to stabilize its basis of reference for length measurements in terms of the yard and its common submultiples for science and technology, unification of the yard standard for these purposes in the British Commonwealth and the United States can no longer be delayed.

With regard to the pound, the values currently in use when expressed in terms of the kilogram are : 1 imperial standard pound $=0.453592338 \mathrm{kgm}$.; 1 Canadian pound $=0.45359243 \mathrm{kgm}$. ; I United States pound $=0.4535924277 \mathrm{kgm}$.

There is evidenee that the imperial standard pound has diminished by about 7 parts in 10 millions since
1846. It is about 2 parts in 10 millions $(0.0014$ grain $)$ smaller than the United States and Canadian pounds, which are defined in terms of the very closely safeguarded international prototype kilogram. Though the discrepancy between the pounds is not at present causing any technical difficulty, the co-existence of independently defined pounds is unsatisfactory in science and technology.

The agreed international values of the yard and the pound fall between the existing United States and British units, and the international yard, which is the same as the Canadian yard, accords exactly with the relationship 1 inch $=25.4 \mathrm{~mm}$., which is already extensively used in Great Britain and abroad for approximate conversions. The adoption of the international values of the yard and the pound will be of particular benefit to all those concerned with accurate measurements of length and mass for scientific and technological purposes in the British Commonwealth and the United States.

\section{OBITUARIES}

\section{Dr. John Jackson, C.B.E., F.R.S.}

DR. JoHN JACKson died in Epsom Hospital on December 9 at the age of seventy-one. His interest in astronomy was aroused when he studied under Prof. Ludwig Becker at the University of Glasgow. There he received a thorough grounding in celestial mochanies and in spherical astronomy. From Glasgow he proceeded to Trinity College, Cambridge, and. was placed among the Wranglers as a result of the Mathematical Tripos Examination in 1912 and was awarded the Tyson Medal and Sheepshanks Exhibition. In 1914 he received the first Smith's Prize.

His attention was directed to the problem of retrograde satellite orbits and, in particular, to the motion of Jupiter's eighth satellite. This satellite had been discovered by Melotte at the Royal Observatory, Greenwich, in 1908. It was the first satellite of Jupiter with a retrograde motion to be discovered and, because of the perturbing action of the Sun, its movement is very complicated. Observations of this satellite are difficult to obtain and are few in number, so that its orbit is even now rather uncertain. In 1914 Jackson was awarded the Mackinnon Studentship of the Royal Society for research on the motion of this satellite, but shortly afterwards he was appointed chief assistant at the Royal Observatory, Greenwich. He remained there for nineteen years and, during that time, he entered fully into all the programmes of observation that were undertaken.

His first important work at Greenwich was concerned with the observations of binary stars that had been made there with the 28 -in. refractor over a period of many years. These observations had been published in the annual volumes of Greenwich Observations, but no use had been made of them. He determined the orbits of a number of these binary systems, and combined the observations made at Greenwich with those that had been made elsewhere. For many of the systems, the periods of which were long, observations have not been extended over sufficient years for orbits to be derived; but the observations of these systems were used to infer their parallaxes and Jackson derived the hypothetical parallaxes of 556 systems.

In 1924 the Shortt free-pendulum clocks were introduced at the Observatory as the standards of time, replacing the regulator clocks that had previously been used. Jackson, in conjunction with W. Bowyer, discussed their performance and showed that, as a result of the nutation of the Earth's axis, sidereal time was not uniform. As a result of these investigations, astronomers have since had to distinguish between apparent and mean sidereal time. Jackson looked into the possibility that the accurate time-keeping of these clocks might provide information about the variability in the rotation of the Earth, but concluded that they were not sufficiently accurate to give trustworthy determination of the variability.

Another important piece of work, undertaken in collaboration with Dr. H. Knox-Shaw, the Radeliffe Observer at Oxford, and his assistant, Mr. Robinson, was a careful reduction of the observations of the Sun, Moon, planets and stars, which had been made at the Radcliffe Observatory, Oxford, during the years 1774-98 by Hornsby. These observations had not been reduced and, for their epoch, were of high accuracy. Such early positions of these bodies are of value in connexion with the determination of the proper motions of the stars, and the investigation of the orbits of the Sun, Moon and planets.

In 1933 Jackson was appointed H.M. Astronomer Royal at the Royal Observatory, Cape of Good Hope, and held that position until his retirement in 1950 , when he returned to Great Britain to take up residence. The Cape Observatory has a long tradition of accurate meridian and astrometric observations. The principal programmes of observation undertaken during Jackson's tenure of office were fundamental meridian observations with the Gill transit circle, the determination of positions and proper motions of stars, the determination of parallaxes of southern stars and the preparation of a photographic catalogue of southern stars between $30^{\circ} \mathrm{S}$. and the South Pole. 